\title{
Influence of Austenite Phase Transformation on Existing Microstructure of Low C-Mn Steel
}

\author{
Shahid Hussain Abro \\ Department of Materials Engineering \\ NED University of Engineering \& Technology \\ Karachi, Pakistan \\ engrabro@neduet.edu.pk \\ Abdul Rauf Jamali \\ Department of Materials Engineering \\ NED University of Engineering \& Technology \\ Karachi, Pakistan \\ engrabdulrauf@neduet.edu.pk
}

\author{
Alidad Chandio \\ Department of Metallurgical Engineering \\ NED University of Engineering and Technology \\ Karachi, Pakistan \\ alidad@neduet.edu.pk \\ Syed Aqeel Shah \\ Department of Metallurgical Engineering \\ NED University of Engineering and Technology \\ Karachi, Pakistan \\ aqeelshah@neduet.edu.pk
}

\begin{abstract}
Cold heading quality CHQ steel is widely used for making small components due to its excellent cold heading response. Austenite nucleation and growth morphology of a commercial CHQ steel has been studied by continuous heating experiments using lead-bath up-quenching at different heating temperatures. Modern optical microscope Olympus GX51, scanning electron microscopy techniques have been deployed to reveal and interpret the microstructure. It was found that at $740^{\circ} \mathrm{C}$ the microstructure shows lack of homogeneity, hence the cold-head-ability of CHQ steel is anisotropic. At high temperatures, in austenite domain, at $60 \mathrm{sec}$, the resultant austenite is highly homogenous. Then the cold-head-ability properties of CHQ steel turned to be isotropic.
\end{abstract}

Keywords-CHQ steel; up-quenching; phase transformation; microstructure; heating rate; austenite

\section{INTRODUCTION}

CHQ steel components have been widely used in automotive, ship and aerospace engineering, thermal plants, etc. Parts such as fasteners, pinions, connecting rods etc. are being manufactured by cold heading. In cold heading operations, the mechanical properties of such components are directly or indirectly controlled by metallurgical aspects like heat treatment. Therefore it is unavoidable to design such parameters in thermal treatment which refines grain size, increases hardness and mechanically stabilize the microstructure by phase transformation. Rapid austenitizing (up-quenching) refines the microstructure, eliminates distortion and provides uniform dispersion of carbide particles in the martensite matrix. In [1], authors worked on CHQ steel and microstructures, compositions and mechanical properties. They proved that good quality of feed stock of CHQ steel wires for increasing tool life should have a uniformly distributed microstructure. Authors in [2] worked on microstructural consequences on CHQ steel grade 1036M. They emphasized their experiments on six microstructures obtained by individual heat treatment analysis. They gave attention to calculate pearlite volume fraction in each sample. The reduction in the pearlite phase can improve the ductility of CHQ steel [2, 3]. Authors in [4] studied the deformation and thermodynamic behavior of EN 10263 CHQ steel. They developed a model which can be imposed to a certain CHQ steel to conduct the elasto-viscoplastic response of that steel. They dealt with ferrite and pearlite microstructural steel. Authors in [5] studied the parameters of rolling and cooling and their impact on microstructure and mechanical properties on different CHQ steels. They observed that the mechanical properties can be enhanced by refinement of ferrite-pearlite grains. They applied fast cooling rate to their steel samples and concluded that fast cooling could prevent the development of gamma-alpha phase transformation. The ferrite fraction manipulates the ductility and the martensite enhances the strength of steels. The combination of both microstructural constitutes can tailor the overall mechanical properties of steels [6].

To the best of our knowledge no previous study on CHQ steel dealt with the austenite phase transformation using upquenching technique. Precise attention has been given in this work to study the austenite formation in CHQ steel. This technique can be employed to other grades. Furthermore, soaking at high temperature in austenitic domain, the heterogeneously formed structure becomes anisotropic in nature, therefore the degree of non-homogeneous anisotropic nature of that steel is proportional to the formation and initiation of austenite phase volume percentage. The distribution of uniform volume percentage of austenite in this steel is mechanically stabilized. Due to uniform distribution of microstructural constituents there will be a minute probability of abnormal grain growth during or after cold heading operations. As a result the steel becomes more favorable for cold heading process [7]. 


\section{EXPERIMENTAL PROCEDURE}

The chemical composition of the experimental steel is shown in Table I.

TABLE I. CHEMICAL COMPOSITION

\begin{tabular}{|c|c|c|c|c|}
\hline $\mathbf{C}$ & $\mathbf{S i}$ & $\mathbf{M n}$ & $\mathbf{N}$ & $\mathbf{C r}$ \\
\hline 0.463 & 0.241 & 0.872 & 0.0049 & 0.25 \\
\hline
\end{tabular}

The steel was heated up to $1200^{\circ} \mathrm{C}$ and was held at that temperature for 120 minutes for solution treatment purposes. After the solution process, the steel was engaged in hot rolling to reduce its thickness. A reduction of $80 \%$ was achieved in four passes. Steel plates were then cut at $800^{\circ} \mathrm{C}$ and after cutting the plates were air-cooled. Specimen cutting was performed to reduce the size of the plates. Lead-bath furnace connected with thermocouple was used (Figure 1).

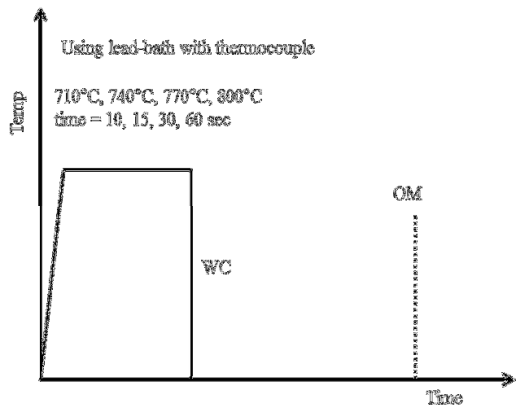

Fig. 1. Rapid heating cycle in lead bath up-quenching.

Austenitizing temperature for up-quenching heat treatment was selected by ASM metals hand book [8]. After austenization the samples were water quenched, then were cut perpendicular to rolling plane direction, mounted and polished according to standard metallographic methods followed by polishing in $1 \mu \mathrm{m}$ and $0.5 \mu \mathrm{m}$ diamond paste as the last step for observing the structural features under optical photomicroscope. The samples were then ultrasonically cleaned in order to remove stubborn contaminants, chemical residuals, dirt or any finger print formed on the surface of the sample during polishing. Two step etching technique, $2 \%$ Nital and $4 \%$ Picric acid was used to reveal the microstructure. The continuous heating experiments were performed in a lead bath as shown in Table II.

TABLE II. CONTINUOUS HEATING EXPERIMENTS.

\begin{tabular}{|c|c|c|}
\hline No & Temperature $\left({ }^{\circ} \mathbf{C}\right)$ & Time $(\mathbf{s e c})$ \\
\hline 1 & 740 & $10,15,30,60$ \\
\hline 2 & 770 & $10,15,30,60$ \\
\hline 3 & 800 & $10,15,30,60$ \\
\hline
\end{tabular}

\section{RESULTS AND DISCUSSION}

\section{A. Microstructure Evolution}

Microstructure, as shown in Figure 2, was carried out by using a solution of $2 \%$ nitric acid diluted in $100 \mathrm{ml}$ ethanol, which is a common etchant used to reveal the ferrite and pearlite grain boundaries. This etchant successfully revealed the grain boundaries and its only drawback was that it was difficult to distinguish eutectoid-ferrite from martensite because both appeared white. To differentiate between transformations such as martensite phase and ferrite phase, 2step etching, $2 \%$ Nital followed by $4 \%$ Picric acid was introduced. Examination of this microstructure under light microscopy was not again satisfying because the distinction of the three phases (ferrite, pearlite and martensite) was still unclear. Color etching technique using LePera solution then was implied to steel samples as described in [9]. A detailed inspection under polarized light in the microscopy successfully disclosed the three phases individually. Then it was easy to determine the volume fraction of austenite with respect to increasing time and temperature. Blue, brown off-white and white colors appeared as ferrite, bainite, martensite and retained austenite respectively. Further details about this tint etching technique of LePera can be found in [9]. The volume fractions of displacive phase of martensite was calculated by using the point counting method described in [10].

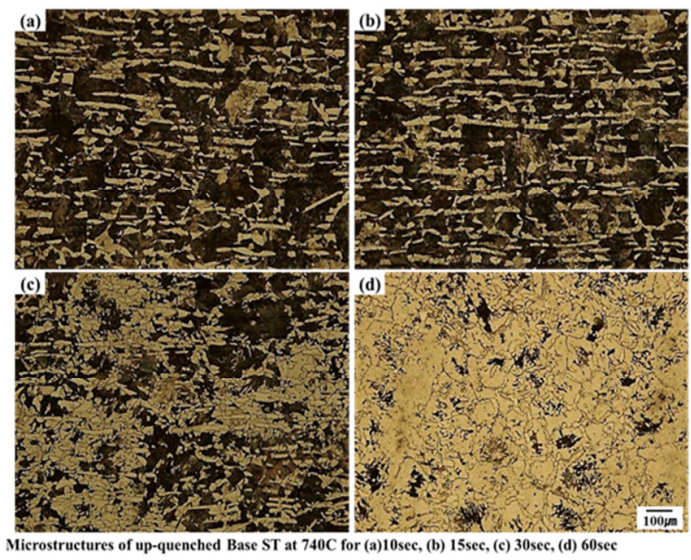

Fig. 2. Microstructure using 2\% Nital

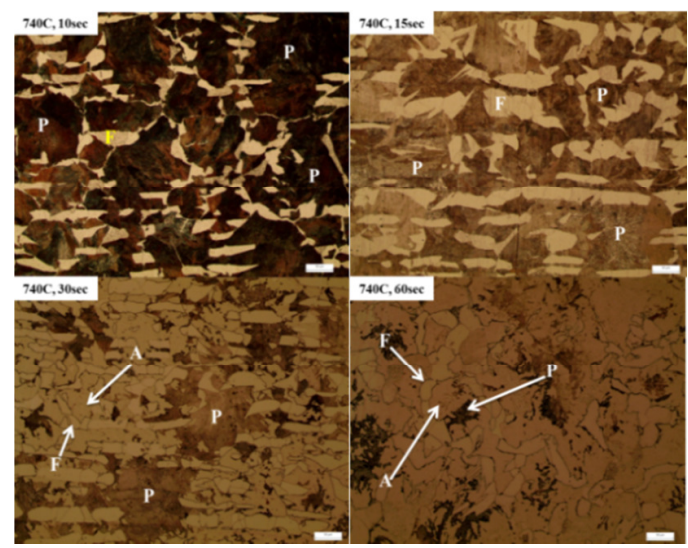

Fig. 3. Micro structure using Lepera etchant.

\section{B. Microstructural Features $T_{0}$}

The as rolled microstructure shown in Figure 4 is a reconstructive phase having ferrite and pearlite only. The territory of pearlite is decorated with allotromorphic ferrite ring commonly termed as pro-eutectoid ferrite. The interface between this ring and pearlite colony acts as the austenite grain 
boundary during transformation. The formation of martensite can take place within this territory because the coordinated motion of military transformation is weak against this ring and cannot cross this grain boundary barrier which behaves as a strong defect. The microstructure obtained at $710^{\circ} \mathrm{C}$, and $10 \mathrm{~s}$, 30 s, 300s holding time during up-quenching is slightly lower than eutectoid temperature which shows formation of larger fraction of "new" ferrite phase volume with respect to increasing holding time.

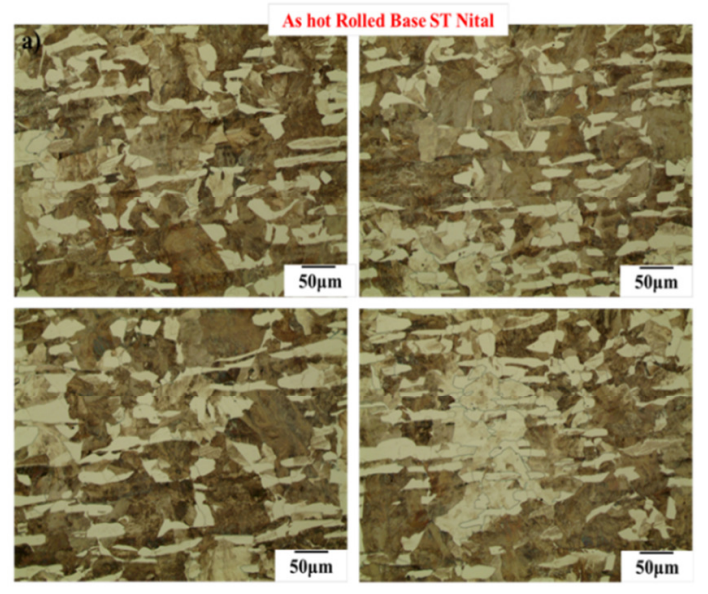

Fig. 4. Reconstructive phase.

At holding time of 300 s, it can be noticed that deformed grains which are relatively enlarged are replaced by a freshly formed bunch of un-deformed ferrite grains which are nearly equiaxed, will nucleate and can grow above the eutectoid temperature which can be named as lower critical temperature or $\mathrm{AC}_{1}$. This recrystallization can take place until the original ferrite grains have been absolutely ingested at 300s holding time. Whenever recrystallization of ferrite grains reaches a higher volume, it is an indication of decreasing hardness and strength but on the other hand ductility may increase. Spheroidizing provides the needed ductility for cold heading [11]. During cold heading operations there is a strong driving force for these soft metals to become hard by cold working phenomenon. Consequently they may lose their softening property and there is a strong driving force of abnormal grain growth and hence microstructure becomes un-identical. In order to decrease the degree of this non-uniformity, steel samples were up-quenched at different austenitic domains in lead bath.

\section{Microstructural Features at $T_{1}\left(740^{\circ} \mathrm{C}, 10,15,30,60 \mathrm{sec}\right)$}

After heating at $740^{\circ} \mathrm{C}$ for scheduled soaking time, the stable recrystallized ferrite become unstable and starts to initiate the nucleation of austenite which moves heterogeneously upon cooling and the civilian transformation turns into military transformation. The extent of which recrystallization completes before the austenite begins to form influences the kinetics of austenite formation and the spread of austenite nuclei in pearlite domain [12]. The insoluble and discarded carbon by austenite and ferrite was not observed, possibly because of the high heating rates in the up-quenching bath, so the majority of austenite formation in this steel was obtained only in pearlite territory. Because of the shorter path it was easy for cementite plate to supply carbon to neighboring ferrite. Evidence of phase transformation can be seen at $30 \mathrm{~s}$ and $60 \mathrm{~s}$ holding time. In the microstructure obtained after $15 \mathrm{~s}$ and 30 s holding, the identification of austenite phase was not easy.

\section{Microstructural features at $T_{2}\left(770^{\circ} \mathrm{C}, 10,15,30,60 \mathrm{sec}\right)$.}

The captured microstructure at $770^{\circ} \mathrm{C}$ can be seen in Figure 5. Austenite nucleation and growth were observed during the entire process but at $10 \mathrm{~s}$ and $15 \mathrm{~s}$ a low volume fraction of austenite was observed. The most possible reason behind this delayed transformation was that up to 10 s holding time there was an incubation period of austenite nucleation. However, with extension of soaking time to $30 \mathrm{~s}$ and $60 \mathrm{~s}$, austenite growth was rapid by consuming pearlite phase. Ferrite packet size has declined in comparison with the $740^{\circ} \mathrm{C}$ microstructure. At $770^{\circ} \mathrm{C}$, the mobility of atoms and the diffusion co-efficient of carbon might have increased. At this temperature it was noticed that a high fraction of pearlite was consumed for austenite mass production, but a very fine and dark trace of the boundary wall had still remained between pro-eutectoid ferrite and pearlite territory which acted as the prior-austenite grain borderline.
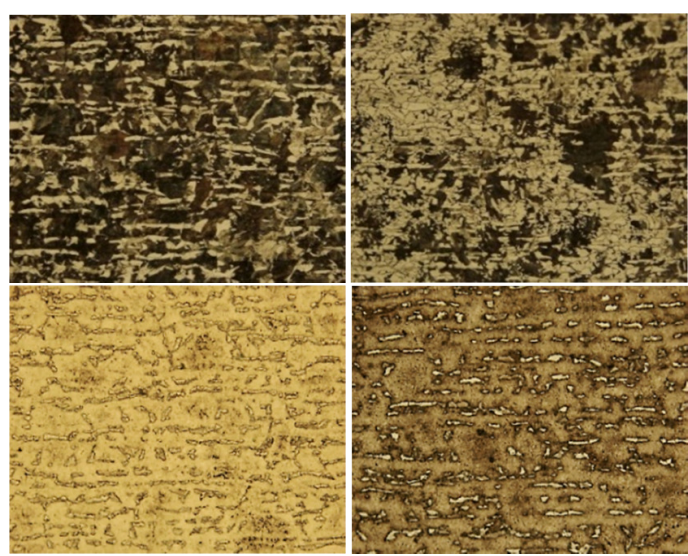

Fig. 5. Austenite nucleation and growth.

\section{E. Microstructural Features at $T_{3}\left(800^{\circ} \mathrm{C}, 10,15,30,60 \mathrm{sec}\right)$}

Micrographs at $800^{\circ} \mathrm{C}$ reveal that the spiral of allotromorhic ferrite which was tightly surrounded at lower temperatures has been broken and the allotromorph slowly decreased and almost disappeared after 60s. The stability of austenite growth becomes stronger thus the degree of isotropy and homogeneity increases. The response during the forming of austenite is much different both at low and high temperatures. At elevated temperature and into the austenite region, the degree of transformation first increased and then decreased because at high temperatures the difference in free energy of the parent phase and product phase drastically declined, however the diffusion coefficient raised at higher level, meaning that minor phase had become major phase and austenite phase has been stabilized. To oversee this logical phase difference at low $\left(740^{\circ} \mathrm{C}\right)$, and high $\left(800^{\circ} \mathrm{C}\right)$ temperature, SEM micrograph has been obtained (Figure 6). Austenite forming increases hardness 
while the subsequent tempering can reduce hardness and improve toughness so both processes simultaneously can be achieved through up-quenching in lead bath. Ausforming results in instantaneous increases in hardness, but this effect is substantially reduced after tempering under conditions which are suitable for fasteners [13].

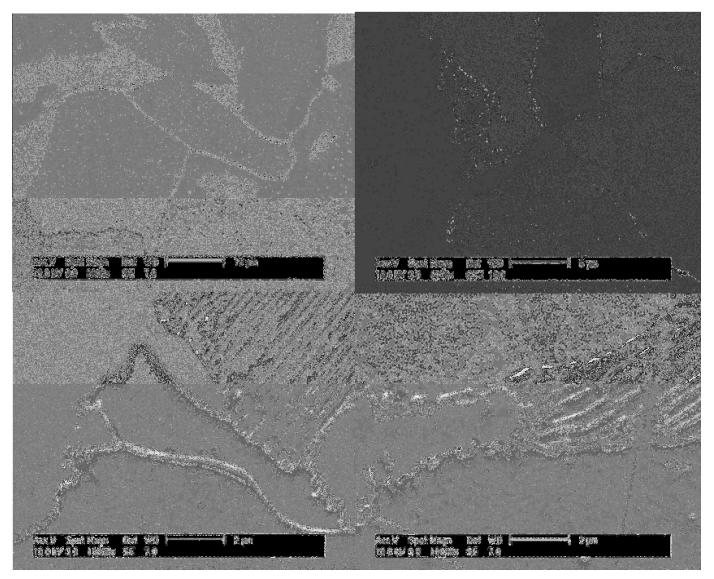

Fig. 6. SEM micrographs

\section{F. Mechanical Stabilization and Glissile Transformation}

To stabilize the austenite thermodynamically, some alloying elements like nickel and manganese are added in steel. Shape deformation on the other hand mechanically stabilizes the structure. This shape deformation involves the movement of glissile interface [14]. To ensure that this movement becomes phase change (displacive) and not just reorientation of the lattice (reconstructive), SEM micrographs at early $\left(740^{\circ} \mathrm{C}\right.$, $60 \mathrm{~s})$ and final stage $\left(800^{\circ} \mathrm{C}, 60 \mathrm{~s}\right)$ have been obtained. It is observed that the displacive transformation grows to a limited size at $740^{\circ} \mathrm{C}$ in which ferrite plate transforms slowly. At final stage the transformation propagates rapidly by forming a martensite plate which has very high strain energy against the dislocations formed during the shape deformation of austenite in invariant plane strain. The mechanical stabilization occurs when the strain required to initiate the stabilization is higher than the opposing dislocation which has a glissile interface that has to cross the dislocation barrier. To calculate this critical strain, (1) can be used:

$$
b \Delta G=\frac{1}{8 \pi(1-v)} G b^{3 / 2}\left(\frac{\varepsilon}{L}\right)^{1 / 2}+\tau_{s} b
$$

where $b$ is the burger vector, $\Delta G$ is free energy, $v$ is Poisson's ratio, $G$ is the shear modulus, and $L$ is the average distance moved by dislocation [15]. Interface is the set of dislocations which allow the two crystals to connect to each other during transformation. This sort of interface is known as glissile interface, must exist between parent and product phase allowing rapid transformation without any diffusion involving in the system. Displacive transformation is only possible when such an interface can be created between two crystals. It can also be observed that an invariant line is left behind between the product and parent phase, meaning there is not any distortion or rotation along this line and hence the atomic arrangement of austenite and martensite match perfectly at that line and the transformation that changes the parent phase (austenite) into the product phase (martensite) leaves at least one line undistorted and unrotated as evidence that the transformation is displacive rather than reconstructive. A detailed investigation of microstructural features at each temperature indicates that all pearlite is digested on the forming of austenite but a small trace of the boundary line is still left behind which is nothing but the p-austenite grain boundary so the gliding of glissile interface is possible within this protected area since the glide of atoms cannot be endorsed across these austenite grain boundaries. Hence, it can be concluded that grain boundaries in the microstructure, presence of dislocations, available interstitial atoms, stacking faults and vacant lattice sites are normally not essential to describe an equilibrium state of phases, however if they are present they can be promoted to the process of phase transformation [16].

\section{CONCLUSIONS}

Three stages during austenite formation in up-quenching of a plastically deformed CHQ steel of $80 \%$ reduced thickness have been studied at different holding temperatures $\left(710^{\circ} \mathrm{C}\right.$, $740^{\circ} \mathrm{C}, \quad 770^{\circ} \mathrm{C}$ and $\left.800^{\circ} \mathrm{C}\right)$. It has been found that microstructural features and mechanical stabilization of plastically deformed steel specimens can be restored to their normal pre-deformed states using up-quenching treatment. During this process recovery, recrystallization and grain growth phenomena occurred and there is a reduction in dislocation density. During the recrystallization formation of new and fresh ferrite, grains free from strain and grain growth increase the average grain size and austenite volume fraction. Austenite formation is possible in pearlite phase and there is no evidence found about the nucleation of austenite at ferrite-ferrite grain interface. Up-quenching refines the grain size so there is a strong tendency to achieve finer microstructure in conventional CHQ steels without additional alloying and heat treatments. Uniform distribution of microstructure can increase the rate of elongation thus CHQ steel coldheability can be enhanced. The rate of nucleation and the rate of growth increases at higher temperatures to form austenite phases in bulk. Rapid heating (up-quenching) is the main cause which could not permit carbides at ferrite-ferrite interface. With increasing holding time and temperature, pearlite packet size decreases and consecutively is turned into martensite upon cooling. Proeutectoid $\alpha$ network first breaks and then slowly disappears at higher heating temperatures.

Finger type growth morphology was observed at $800^{\circ} \mathrm{C}$. This sort of growth morphology is observed on pearlite laths perpendicular to the ferrite/pearlite grain boundary and is not observed if the laths are parallel to it. In the parallel case, there is strong tendency for bainite structure to be formed. The identicality and consistence of microstructural features is best executed by continuous heating in the high heating zone which is best suited to study these microstructural features at lowest possible time period to save the other parameters.

\section{REFERENCES}

[1] T. Das J. Y. Li M. Painter E. Summerville, "Evaluation of two AISI 4037 cold heading quality steel wires for improved tool life and product 
quality", Journal of Materials Engineering and Performance, Vol. 11, No. 1, pp. 86-91, 2002

[2] M. A. Xiaoyu,"Effect of Microstructure on the Cold Headability of a Medium Carbon Steel", ISIJ International, Vol. 44 No. 5, pp. 905-913, 2004

[3] R. Hill, "Annealing: The First Step in Cold Forming", Wire Journal International, Vol. 17, No. 7, pp. 95-97, 1984

[4] J. Ramo, V. T. Kuokkala, T. Vuoristo, "Influence of strain rate and adiabatic heating on the deformation behavior of cold heading steels", Journal of Materials Processing Technology, Vol. 209, No. 11, pp. 51865194, 2009

[5] Y. H. Lee, J. S. Kwon, D. L. Lee, "Study on the formation of ferritecementite microstructure by strain induced dynamic transformation in medium carbon steels", Materials Science Forum, Vol. 539-543, pp 4267-4271, 2006

[6] J. Huang, W. J. Poole, M. Militzer, "Austenite formation during intercritical annealing", Metallurgical and Materials Transactions A, Vol. 35, No. 11, pp. 3363-3375, 2004

[7] A. Sabih, J. A. Nemes, "Internal ductile failure mechanisms in steel cold heading process", Journal of Materials Processing Technology, Vol. 209, No. 9, pp. 4292-4311, 2009

[8] S. Tajik, M. Ahmad, I. Ahmad, J. Khan, "The effect of heat treatment on microstructure and mechanical properties of steels", Journal of Engineering and Applied Sciences, Vol. 17, No. 2, pp. 206-211, 1998

[9] E. Girault, P. Jacques, P. Harlet, K. Mols, J. Van Humbeeck, E. Aernoudt, F. Delannay, "Metallographic Methods for Revealing the Multiphase Microstructure of TRIP-Assisted Steels", Materials Characterization, Vol. 40, No. 2, pp. 111-118, 1998

[10] R. L. Higginson, C. M. Sellars, Worked Examples in Quantitative Metallography, Maney, 2003

[11] J. W. Christian, Theory of Transformations in Metals and Alloys, Pergamon, 2002

[12] V. I. Savran, Y. Van Leeuwen, D. N. Hanlon, C. Kwakernaak, W. G. Sloof, J. Sietsma, "Microstructural features of austenite formation in C35 and C45 alloys", Metallurgical and Materials Transactions A, Vol. 38, No. 5, pp. 946-955, 2007

[13] S. Lee, S. J. Lee, B. C. De Cooman, "Austenite stability of ultrafinegrained transformation-induced plasticity steel with Mn partitioning", Scripta Materialia, Vol. 65, No. 3, pp. 225-228, 2011

[14] S. Chatterjee, H. S. Wang, J. R. Yang, H. K. D. H. Bhadeshia, "Mechanical stabilisation of austenite", Materials Science and Technology, Vol. 22, No. 6, pp. 641-644, 2006

[15] S. J. Tajik, J. Z. Khan, M. Pervaz, I. Ahmad, "Effect of cooling rate and austenite temperature on the mechanical properties of commercial steels", Journal of Engineering and Applied Sciences, Vol. 15, pp. 6168, 1996

[16] S. Q. Yuan, G. L. Liang, "Dissolving behaviour of second phase particles in Nb-Ti microalloyed steel", Materials Letters, Vol. 63, No. 27, pp. 2324-2326, 2009

[17] Y. Z. Zhu, Z. Zhu, J. P. Xu, "Grain boundary segregation of minor arsenic and nitrogen at elevated temperatures in a microalloyed steel", International Journal of Minerals, Metallurgy, and Materials, Vol. 19, No. 5, pp. 399-403, 2012 